\title{
Language Fluency and Study Abroad Adaptation
}

\author{
Victor Savicki \\ Western Oregon University
}

\section{Carmen Arrúe \\ AHA International, Oviedo, Spain}

\section{Frauke Binder}

AHA International, Vienna, Austria

Many study abroad programs require language proficiency, emphasize language learning, or otherwise support the development of language skills for their students. A general assumption underlying this attention to foreign language acquisition is that access to the host culture is increased as students are able to converse with host nationals using that foreign language (Edelstein, 2009). Likewise, some theorists have promoted the idea that being able to converse and think in a foreign language gives the speaker special access to the manner in which native speakers might conceptualize and construe their reality (Hill \& Mannheim, 1992). Yet there is some debate about the centrality of language learning in the process of developing intercultural competence. Bennett (2008) for example, says that a fluent foreign language speaker without intercultural competence may be a "fluent fool" who knows how to unknowingly insult host nationals using perfect vocabulary and grammar (p. 17).

The current study examines the relationship of language fluency to a variety of outcomes of study abroad. The general question posed is "Does the requirement for foreign language fluency lead to better study abroad outcomes?" The outcomes examined roughly follow Ward's ABC model of acculturation (Ward, 2001, Ward, Bocher , \& Furnham, 2000). This model suggests that study abroad outcomes fall into three categories: affect, behavior, and cognition. Affect (A) is mostly measured by psychological constructs related to the mental and emotional well-being of study abroad students. The behavioral aspect (B) is measured by attending to the ease and completeness with which a student "fits in" with the host culture. Cognition (C) is measured by examining aspects of the students' social identification. All three outcomes 
will be assessed in the current study, with special emphasis on the behavioral variable of sociocultural adaptation. The general hypothesis is that prior language fluency will enhance student study abroad outcomes on all of the $\mathrm{ABC}$ categories.

A brief review of relevant literature will set the context for specific hypotheses and subsequent research findings.

\section{Levels of language requirement}

Engle and Engle (2003) illustrate the central position of language learning in study abroad programs. They suggest that language learning and cross-cultural competence go hand-in-hand in most modern study abroad efforts. "Entry target language competence" (Engle \& Engle, 2003 p. 8) ranks second of the seven defining characteristics of overseas programs, preceded only by length of stay. Increasing the level of target language competence required contributes positively to the evaluation of a program's level of comprehensiveness and degree of cultural immersion. In the current research, the study abroad program with a requirement for entry target language competence also offered courses in the language of the host culture. Thus, it would rank higher in immersion than this study's comparator program according to the Engle and Engle (2003) schema.

\section{Distinctions between language and cultural learning}

Language learning and cultural learning do not necessarily go hand in hand. Lange and Paige (2003) indicate that the inclusion of culture in language learning is "an unresolved issue" (p. x). Likewise, Deardorff (2008) found that experts in the field of intercultural competence, on average, did not rate language fluency as a vital prerequisite for developing intercultural competence. While there is some evidence that study abroad students with more advanced language education were better prepared both linguistically and culturally to benefit from interaction with native speakers (Allen \& Herron, 2003), the actual engagement with a study abroad culture was more strongly influenced by affective variables such as motivation, levels of anxiety, and selfperceptions of fluency (Churchill \& Dufon, 2006). As Isabelli-García, (2006) states, although research generally confirms that immersion in a foreign culture enhances student second language acquisition, " learners may not magically become fluent speakers simply by being surrounded by the target language" (p. 231). Engle and Engle (2003) also separate language and cultural learning in their list of features of study abroad programs by suggesting that "Provisions for guided/structured cultural interaction and experiential learning" and "Guided 
reflection on cultural experience" (p. 8) are also important components for evaluating study abroad programs. The linkage between language fluency and intercultural competence remains murky.

To date, language learning research has most often focused on the impact of study abroad on aspects of language acquisition. That is, the causal linkage has focused on how interacting with native speakers in the study abroad environment can increase aspects of vocabulary, pragmatics, register, grammar, etc. (Paige, Jorstad, Siaya, Klein \& Colby, 2003). In addition, a longitudinal study by Norris and Steinberg (2008) found that study abroad students who participated in more intense second language learning programs reported a significantly stronger long term commitment to foreign language study than did students with native language only or combined foreign/native language course requirements.

On the other hand, from the cultural perspective, the focus has been on language as a tool for the learning and expression of cultural competence. For example, Brown (cited in Norris \& Steinberg, 2008) reported that students with more language skills had an easier adjustment to their study abroad setting. Engle and Engle (2004) found "moderate level of coherence" between student improvements in language learning and intercultural sensitivity over one semester; however, that association contained anomalies, and was lost over a two semester sojourn. Conceptually, an emphasis on the impact of sociolinguistic features rather than language fluency itself has been seen as key to improving intercultural competence (Deardorff, 2008; Saville-Troike, 2003). Learning the rules and social meanings of how language is employed in a specific culture may be more important than correct grammar and syntax. In general, the impact of language fluency on study abroad outcomes seems somewhat muted. For example, Norris and Steinberg (2008) found that students from programs with a wide range of foreign language requirements and curricular expectations showed no significant differences in over half of their measured study abroad outcomes. Even students in programs with no foreign language component at all still benefitted from their study abroad experience. There is still much to be learned about how language and cultural learning may support and/or impede each other in the study abroad context.

The current study aims to shed light on these issues by answering the call by Norris and Steinberg (2008) for research comparing study abroad programs with different language requirements and languages of instruction, and by integrating a range of study abroad outcome measures that examines how these differences may influence student affective, behavioral, and cognitive study abroad consequences. 


\section{Hypotheses}

In brief, for the purposes of this research, we hypothesize that students in a program with an entry target language competence requirement will enjoy better study abroad outcomes than those in a program without one. Specific research hypotheses are listed below.

1. Study abroad students with a requirement for fluency in the host culture language will have more contact with people in the host culture than study abroad students without a requirement for language fluency.

2. Study abroad students with a requirement for fluency in the host culture language will have better outcomes in terms of psychological adjustment, affect, social identification, and sociocultural adaptation at the end of their sojourn than study abroad students without a requirement for language fluency.

3. Study abroad students with a requirement for fluency in the host culture language will adapt to the host culture with less difficulty throughout their sojourn than will study abroad students without a requirement for language fluency.

\section{Methods}

\section{Participants and programs}

Study abroad students from U.S. universities in the Pacific Northwest and Midwest $(\mathrm{n}=38)$ were enrolled in two different programs (Vienna, Austria $\mathrm{n}=$ 11; Oviedo, Spain $n=27$ ). The average age was $20.61 ; 68 \%$ were female; class standing distribution was $45 \%$ Seniors, 50\% Juniors, and 5\% Sophomores.

The two programs, evaluated and overseen by the same study abroad provider and university consortium, were comparable in terms of duration, home stay living arrangements and requirements for a semester long intercultural communication course, as well as academic structure and requirements. The major difference between programs was that the Oviedo program required some level of Spanish language proficiency prior to entry; whereas the Vienna program had no prior language requirement. The Oviedo program also offered some academic courses in Spanish. Both programs required host culture language instruction based on students' competency. The intercultural communication class in both settings included culture specific and culture general information as well as guided reflection on cultural experience. 


\section{Measures}

Nine different measures were employed to assess study abroad outcomes, as well as individual student characteristics and experiences that might be related to those outcomes.

Sociocultural Adaptation Scale (SCAS). In the SCAS Ward and Kennedy (1999) have identified a list of encounters, and issues that may be relevant to sociocultural adjustment. Respondents rate their difficulty in adjusting to cultural situations using a five point Likert scale with $1=$ No difficulty to 5 = Extreme difficulty. A brief sample of their twenty nine item scale includes "Making friends," "Using the transport system," "Going shopping," "Dealing with unsatisfactory service," "Getting used to the local food/finding food you enjoy," "Dealing with people in authority," "Understanding the locals' world view" (Ward \& Kennedy, 1999 p. 663). Reliability based on Cronbach's alpha for the current sample was .718 to .888 over repeated measurement. In addition, Ward and Kennedy (1999) factor analyzed their scale and found two factors: Cultural Empathy and Relatedness (thirteen items, 32\% of variance), and Impersonal Endeavors and Perils (seven items, 9\% of variance).

American Identity Measure (AIM). The AIM (Meyer-Lee \& Evans, 2008 ) is a social identification scale developed to assess study abroad students' sense of self in terms of their feelings of belonging to and attitudes toward the larger U.S. society. This ten item scale derives from the work of Phinney and colleagues (Phinney, 1992; Phinney \& Devish-Navarro, 1997) Students responded on a four point Likert scale from $1=$ Strongly Disagree to $4=$ Strongly Agree. Two factor analyzed sub-scales assessed the two components of American Identity. Factor 1 (five items), Commitment/Affirmation (CA), assessed the attachment and personal investment to being an American with items such as "I have a strong sense of being an American," and "Being an American plays an important part in my life." Factor 2 (five items), Exploration/Search (ES), assessed the process of seeking information and experiences relevant to defining one's own "American-ness" with items such as "I have spent time trying to find out more about what being American means," and "I have sometimes wondered about the meaning or implications of being American." Alphas for the current sample were CA $=.749, \mathrm{ES}=.809$.

Brief Symptom Inventory (BSI). Psychological well-being/strain was measured based on four sub-scales from the BSI (Derogatis \& Melisaratos, 1983). The five to six item symptom cluster scales included were Somatization: distress arising from perceptions of bodily dysfunction; Depression: dysphoria and lack of motivation and energy; Anxiety: nervousness, panic attacks, apprehension, dread; and Hostility: thoughts, feelings or actions of anger. Coefficient alphas for the sub-scales were Somatization .807, Depression .685, 
Anxiety .625, Hostility .744.

Positive and Negative Affectivity Schedule (PANAS). Positive and negative mood were assessed with the PANAS; (Watson, Clark, \& Tellegen, 1988). The Positive Activation subscale lists ten adjectives related to positive mood (e.g. active, alert, attentive). The Negative Activation subscale lists ten adjectives related to negative mood (e.g. afraid, ashamed, distressed). Participants were asked to rate the extent to which they had felt each of these emotions over the previous three months. Ratings were made on a five point Likert scale, ranging from $1=$ Very slightly or not at all to $5=$ Extremely. Alphas for the current sample were Positive Activation, .853; Negative Activation, .698.

The Appraisal of Life Events (ALE) scale. The ALE (Ferguson, Matthews, \& Cox, 1999) assesses cognitive appraisal of stressful situations via three dimensions: Challenge (six items), the degree to which the environment is perceived as one that allows for personal growth and development through potential mastery of stressors; Threat (six items), the degree to which the environment is perceived as hostile, apt to generate anxiety, and may be potentially harmful; and Loss (four items), the potential for suffering and sadness. Participants were asked to appraise "my study abroad experience" on sixteen adjectives (e.g. stimulating, exciting, fearful, hostile, depressing, painful) using a five point Likert scale ranging from $1=$ Not at all, to $5=$ Very much so. Alphas for the current sample were Challenge, .762; Threat, .912, and Loss, .760.

Intercultural Adjustment Potential Scale (ICAPS). The ICAPS consists of fifty five items with responses given on a scale ranging from $1=$ Strongly Disagree to 7 = Strongly Agree. A total score (ICAPS Total) was computed by summing all items (twenty four reverse coded) with higher scores indicating greater adjustment potential (Matsumoto, et al., 2001). This scale has demonstrated predictive validity for adjustment to a new culture based on peer and expert interviewer ratings, as well as self and subjective ratings (Matsumoto, et al., 2001 p 492). Four factor scores were also derived - Emotion Regulation (ER): the ability to modulate one's emotional reactions to avoid employing psychological defenses, Openness (OP): the ability to engage in learning about the new culture, Flexibility (FL): being free of over-attachment to previous ways of thinking and willingness to tolerate ambiguity, and Critical Thinking (CT): the ability to generate creative, new hypotheses about incidents in the new culture that go beyond one's home cultural framework. All five ICAPS scores were transformed to T-scores with a mean of fifty and standard deviation of ten based on a normative sample. The authors of the scale reported alphas of .783 for the ICAPS Total, .638 for Emotional Regulation, .601 for Openness, .568 for Flexibility, .433 for Critical Thinking (Matsumoto, et al., 2001). 
General Contact levels. Percent of contact with individuals from different cultures was measured by student responses to the following question given at the end of the study abroad term:

When thinking about the last month, please estimate the percent of time you spent in face to face contact with the following kinds of people (the percentages should add to $100 \%$ ). In situations in which you may encounter more than one type of person at once (e.g. host culture teacher in a class with fellow American students), please count that as contact with the host culture.

The response alternatives were, 1. American students, 2. People in the host culture (teachers, shop keepers, other students, etc.), and 3. People of a different culture (neither home nor host culture).

Specific contact levels. Several specific contact options for the host culture were assessed using a six point Likert scale from $0=$ Never to $5=$ Daily. Crossculture contact options include items such as "Interact with other culture people in your accommodations (home stay or apartment)," "Interact with other culture people in daily situations (shop keepers, bartenders, taxi drivers, etc.)."

Prior exposure to other cultures. Several questions concerning student prior exposure to other cultural influences were asked, e.g. Number of weeks of previous foreign travel, Years of foreign language study, Number of friends from other cultures.

\section{Procedures}

Students responded to measures voluntarily with assurance of confidentiality. Within one month of departure to their study abroad locations, students were mailed a questionnaire that contained the ICAPS, AIM, a version of the SCAS asking for their anticipation of difficulty with those items, and a request for demographic and exposure to other cultures information. They brought the completed questionnaire to be collected at their study abroad site.

While on their study abroad sojourn, students completed the SCAS on weeks two and five, as well as at the end of the term. Other end-of-the-term measures included the BSI, ALE, PANAS, AIM, and both general and specific cultural contact questions.

\section{Results}

The Oviedo and Vienna groups were not different from one another in terms of average age, gender composition, amount of previous foreign travel, previous foreign exchanges, or friends from other ethnic groups. Significant differences were reported, as expected, in years of university language study 
with Oviedo students having studied 1.69 years versus .98 years for Vienna students $(F=4.925, p<.05)$. A reverse significance, however, emerged in years of foreign language study in high school with the Vienna students studying 3.91 years versus 2.67 years for Oviedo students $(F=12.065, p<.01)$. The Oviedo group also had a significantly higher proportion of students with Senior class standing $\left(\mathrm{X}^{2}=6.029, p<.05\right)$.

The following discussions reflect results of hypothesis testing, as well as a post hoc examination of factors contributing to reduced sociocultural adaptation outcomes.

\section{Language fluency and cultural contact}

Hypothesis 1 stating that the requirement for fluency in the language of the study abroad culture will be related to higher percentages of student contact with members of the host culture is rejected. Although this hypothesis is rejected in a general sense, some interesting specifics help to describe the actions of the two language requirement groups. First, as seen in Table 1, the two groups were not different in percent of reported general contact with Host Culture Nationals, nor in contact with their American study abroad peers, nor in contact with people from cultures beyond the host culture. Interestingly, the difference between the groups is only marginally significant for the specific contact type of "Speaking the host language outside of class," $(p<.10)$. The Oviedo host culture language speakers were more likely to have made special arrangements during their stay (e.g. music lessons) and had reported significantly more travel within host country. The Vienna group, in contrast, travelled more frequently outside their host country and spent significantly more time using public transportation. Although some of these contrasts may be due to site specific differences (e.g. easy access to air and train travel), they do point out that the type of specific interpersonal contacts that study abroad students make may be related, to some degree, to whether or not they can use the host culture language as a means to make that contact. 
Table 1. Means and SDs for Percent of Types of Cultural Contact by Group

\begin{tabular}{|c|c|c|c|c|c|}
\hline Group & Oviedo & & Vienna & & \\
\hline Contact types & Mean & SD & Mean & SD & $\mathrm{F}$ \\
\hline \multicolumn{6}{|l|}{ General Contact } \\
\hline & 50.538 & 15.414 & 55.273 & 13.770 & \\
\hline American Peers & & & & & 0.619 \\
\hline Host Culture Nationals & 37.692 & 15.892 & 31.000 & 8.426 & 1.569 \\
\hline Other Culture Nationals & 11.769 & 11.196 & 13.727 & 8.533 & 0.225 \\
\hline \multicolumn{6}{|l|}{ Specific Contact } \\
\hline & 4.154 & 1.345 & 3.364 & 1.286 & \\
\hline Host family interaction & & & & & 2.141 \\
\hline Daily situations (shopkeepers etc) & 3.769 & 1.166 & 3.455 & 1.128 & 0.447 \\
\hline Social situations (clubs, parties, etc) & 3.308 & 0.855 & 2.636 & 1.567 & 1.773 \\
\hline Public transportation & 2.308 & 1.494 & 4.000 & 1.549 & $7.394^{*}$ \\
\hline Conversation partners & 2.231 & 1.589 & 1.545 & 1.916 & 0.918 \\
\hline Students from different cultures & 3.077 & 1.498 & 2.364 & 1.286 & 1.534 \\
\hline $\begin{array}{l}\text { Special arrangements (e.g. music } \\
\text { lessons) }\end{array}$ & 2.538 & 1.613 & 1.182 & 0.982 & $5.903^{*}$ \\
\hline Speak host language outside of class & 3.538 & 1.198 & 2.455 & 1.440 & $4.057+$ \\
\hline Travel within host country & 3.308 & 0.751 & 2.273 & 0.905 & $9.391^{* *}$ \\
\hline Travel outside host country & 1.154 & 1.144 & 3.455 & 0.820 & $30.949^{* *}$ \\
\hline
\end{tabular}

$+p<.10,{ }^{*} p<.05,{ }^{* *} p<.01$

\section{Language fluency and affective and cognitive study abroad outcomes}

Following Ward's (2001) formulation that study abroad outcomes can be divided into affective, behavioral, and cognitive aspects, we first examine affect and cognition. Hypothesis 2 stating that students with a requirement for language fluency will show better study abroad outcomes for affect and cognition is rejected. As shown in Table 2 the two groups did not differ significantly on end-of-the-term measured appraisal of stress, reported psychological symptoms, positive or negative affect (affective variables), or American identity (cognitive variable). These results suggest that language fluency may not be the defining variable that is related to study abroad outcomes at the psychological level. A sense of well-being and the evaluation of one's identity within the study abroad experience may have more potent influences than the prior ability to use the language of the host culture. 
Victor Savicki, Carmen Arrúe, Frauke Binder

Table 2. Means and SDs for Affective and Cognitive Outcomes by Group

\begin{tabular}{llllll}
\hline Group & Oviedo & & Vienna & & \\
\hline Outcome variables & Mean & SD & Mean & SD & F \\
\hline Appraisal of Stress & 3.962 & 0.743 & 3.833 & 0.610 & 0.208 \\
Challenge & & & & & \\
Threat & 1.051 & 0.768 & 1.076 & 0.914 & 0.005 \\
Loss & 0.615 & 0.428 & 0.795 & 0.843 & 0.457 \\
Mood & 18.615 & 3.330 & 19.182 & 4.119 & 0.139 \\
Negative affect & & & & & \\
Positive affect & 38.615 & 5.059 & 35.364 & 6.071 & 2.052 \\
Psychological Symptoms & 0.513 & 0.422 & 0.561 & 0.282 & 0.102 \\
Anxiety & & & & & \\
Hostility & 0.338 & 0.171 & 0.509 & 0.274 & 3.470 \\
Somaticism & 0.637 & 0.672 & 0.701 & 0.662 & 0.055 \\
Depression & 0.628 & 0.320 & 0.848 & 0.535 & 1.555 \\
American Identity & 3.185 & 0.608 & 3.000 & 0.820 & 0.400 \\
Commit/Affirm & & & & & \\
Explore/Search & 2.785 & 0.640 & 2.491 & 0.802 & 0.997 \\
\hline
\end{tabular}

\section{Language fluency and behavioral study abroad outcomes}

At the behavioral level, Ward and Kennedy (1999) suggest that the ability to "fit in" with the culture is a meaningful measure of outcome of a sojourn in another culture. Hypothesis 3 stating that students with the requirement for language fluency will show less difficulty fitting in with the host culture at all points during their study abroad sojourn than will students without the language fluency requirement is rejected. As Table 3 indicates for SCAS Total, although the Oviedo group showed less difficulty with fitting in both in anticipation of their study abroad and at the second week, the experimental groups were not significantly different from each other until the end of the term when the results were opposite of the Hypothesis 3 prediction. The group with the requirement for language fluency showed significantly more overall difficulty fitting in to the host culture at the end of their sojourn $(p<.05)$. Figures 1 and 2 give a graphic interpretation of these results also showing significantly higher difficulty for the Oviedo group at week five for the Impersonal Endeavors and Perils factor $(p<.05)$, and at the end of the term for the Cultural Empathy and Relatedness factor $(p<.05)$. 
Table 3. Means and SDs by Groups over four time periods

\begin{tabular}{|c|c|c|c|c|c|}
\hline \multirow{2}{*}{$\begin{array}{l}\text { Group } \\
\text { SCAS Measures }\end{array}$} & \multicolumn{2}{|l|}{ Oviedo } & \multicolumn{3}{|c|}{ Vienna } \\
\hline & Mean & SD & Mean & SD & $\mathrm{F}$ \\
\hline \multicolumn{6}{|l|}{ Pre-departure } \\
\hline SCAS Total & 2.148 & 0.580 & 2.285 & 0.421 & 0.488 \\
\hline SCAS Cultural Empathy and Relatedness & 2.169 & 0.565 & 2.000 & 0.522 & 0.454 \\
\hline SCAS Impersonal Endeavors and Perils & 2.693 & 0.524 & 2.529 & 0.421 & 0.904 \\
\hline \multicolumn{6}{|l|}{ Week 2} \\
\hline SCAS Total & 1.756 & 0.341 & 2.115 & 0.354 & 1.427 \\
\hline SCAS Cultural Empathy and Relatedness & 1.865 & 0.437 & 2.129 & 0.460 & 0.156 \\
\hline SCAS Impersonal Endeavors and Perils & 1.813 & 0.355 & 1.816 & 0.301 & 0.206 \\
\hline \multicolumn{6}{|l|}{ Week 5} \\
\hline SCAS Total & 1.775 & 0.376 & 1.697 & 0.279 & 0.933 \\
\hline SCAS Cultural Empathy and Relatedness & 1.774 & 0.446 & 1.831 & 0.337 & 0.000 \\
\hline SCAS Impersonal Endeavors and Perils & 1.718 & 0.455 & 1.410 & 0.278 & $4.550^{*}$ \\
\hline \multicolumn{6}{|l|}{ End of Term } \\
\hline SCAS Total & 2.117 & 0.292 & 1.867 & 0.323 & $4.792^{*}$ \\
\hline SCAS Cultural Empathy and Relatedness & 2.284 & 0.441 & 1.887 & 0.403 & $5.432^{*}$ \\
\hline SCAS Impersonal Endeavors and Perils & 2.407 & 0.391 & 2.316 & 0.490 & 0.041 \\
\hline
\end{tabular}

$* p<.05$

A repeated measures analysis showed significant changes in sociocultural adaptation over time for both groups, as seen in Figures 1 and 2 (Sociocultural Adaptation Total $(p<.001)$, Cultural Empathy and Relatedness $(p<.05)$, Impersonal Endeavors and Perils $(p<.001))$. The groups were not significantly different from each other overall in how they changed. For both Oviedo and Vienna students there was a significant decrease in difficulty in the Impersonal Endeavors and Perils factor between pre-departure and week two $(p<.001)$ and a significant increase in difficulty in the Impersonal Endeavors and Perils adaptation factor between week five and the end of the term $(p<.001)$. The groups are significantly different from each other on Impersonal Endeavors and Perils at week five $(p<.05)$ Also for Vienna students there was a significant decrease in difficulty in the Sociocultural Adaptation Total score from predeparture to the end of the term $(p<.01)$. For Oviedo students there was a significant increase in difficulty associated with the Cultural Empathy and Relatedness factor between week five and the end of the term $(p<.01)$. For both groups there was a significant decrease in difficulty in the Cultural Empathy and Relatedness factor between weeks two and five $(p<.05)$. Thus, not only was the requirement for language fluency not related to fitting in easier; it was, further, associated with more difficulties of fitting in over several categories. 
Figure 1. Sociocultural Adaptation Scale Total Scores for Oviedo and Vienna groups at four points during their sojourn.

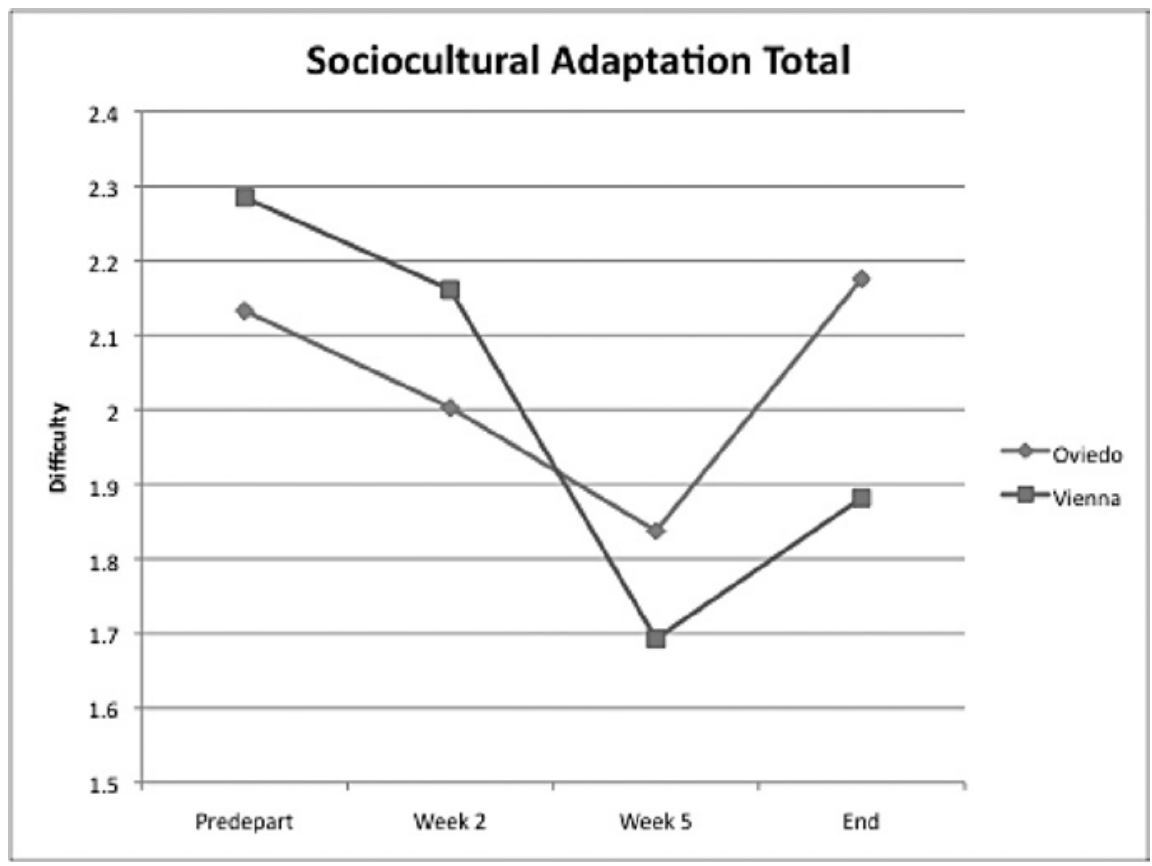

Figure 2. SCAS Factor Scores for Oviedo and Vienna groups at four points during their sojourn

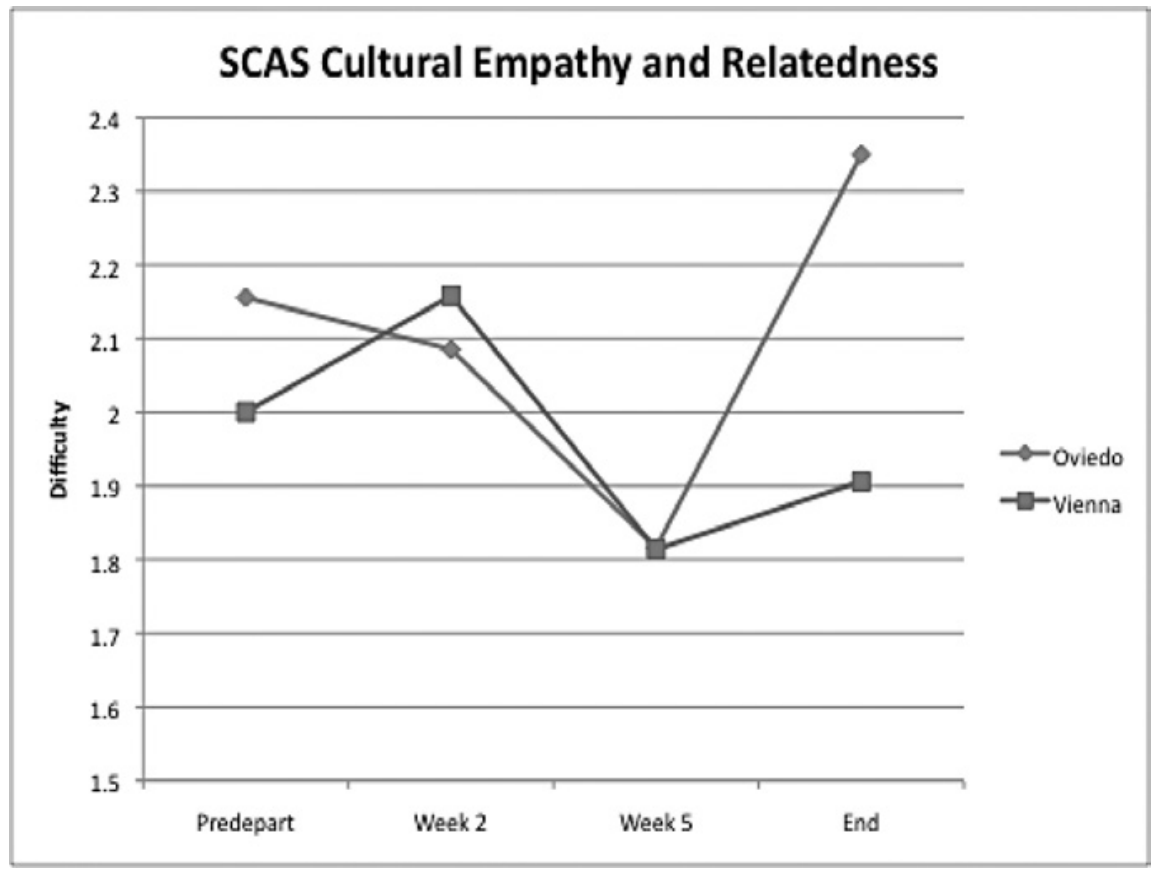




\section{Predictors and correlates of lower sociocultural adaptation}

On the basis of the unexpected findings regarding the relationship of the language requirement and sociocultural adaptation, a post hoc analysis was done to discover predictors and correlates of sociocultural adaptation. For this analysis data from the two study abroad programs were combined. Table 4 shows correlations of sociocultural adaptation total and factor scales with other research variables.

Difficulties in sociocultural adaptation may be more related to students' abilities to accept the host culture or at least to suspend perceptions through the lns of the home culture than to use the host culture language. When all students were considered together, pre-departure commitment to their American Identity seemed to relate to perceived difficulties in adapting to the host culture at the end of their sojourn. The pre-departure measure of American Identity Commitment/Affirmation (AICA Pre) correlated significantly with Post SCAS Total $=.491, p<.02$; with Post SCAS Cultural Empathy= $.399, p<.05$; and with Post SCAS Endeavors and Perils $=.422, p<.04)$. An examination of Table 4 indicates that pre-departure commitment to American Identity is related to lower Flexibility $(r=-.386, p<.02)$, higher appraisal of cultural experiences as Threats $(r=.554, p<.01)$, stronger Negative Affect $(r=$ $.435, p<.05)$ and higher Anxiety $(r=.435, p<.05)$. A strong commitment to American Identity prior to departure may set the stage for viewing encounters with a foreign culture in a more fixed manner, for experiencing differences as potentially unsafe, and for some level of anxiety and unhappiness during the sojourn. Such an experience might lead students to maintain a psychological distance from the host culture, with an associated lessening of empathy and relatedness.

Additionally, pre-departure levels of American Identity Exploration/ Search (AIES Pre) was related to both overall difficulties with end of sojourn sociocultural adaptation and with the Impersonal Endeavors and Perils factor scale (Post SCAS Total $=.456, p<.03$; Post SCAS Endeavors and Perils= .549, $p<.01)$. For the AIES Pre scale a somewhat different pattern of correlates emerged. Table 4 shows AIES Pre correlated significantly with the appraisal of acculturative stress as a Threat $(r=.481, p<.02)$, Critical Thinking $(r=.360, p<$ $.03)$, Negative Affect $(r=.508, p<01)$, and Depression $(r=.520, p<.01)$. In the case of an inclination to think about one's American Identity, the very process of such examination may induce fearful appraisals, and unhappy feelings as well as a sense of not fitting in. A multiple regression mediation analysis (Baron \& Kenney, 1986) indicated that AIES Pre mediated the relationships between the Post SCAS Endeavors and Perils factor scale and Threat, as well as Negative Affect. That is, a pre-departure tendency of students to explore and 
ponder their American Identities may provide the link between negative affect and a stronger sense of difficulty with the day-to-day process of fitting into a foreign culture. The American identity factors at the end of the term were only related to the SCAS Impersonal Endeavors and Perils factor (AICA Post $r=$ $.507, p<.05$; AIES Post $r=.672, p<.01$ ).

For both the Commitment/Affirmation and the Exploration/Search factors of the American Identity Measure, student pre-departure tendencies related to difficulties in fitting into the host culture almost three months later. It may be for those students whose cultural identities are more well set, the task of adapting to a different culture is fraught with more difficulty than for those whose identities are less well defined. Indeed, the very process of thinking about one's cultural identity may make one more vulnerable to symbolic anxiety and to inter-group anxiety (Stephan, Stephan, \& Gudykunst, 1999). 


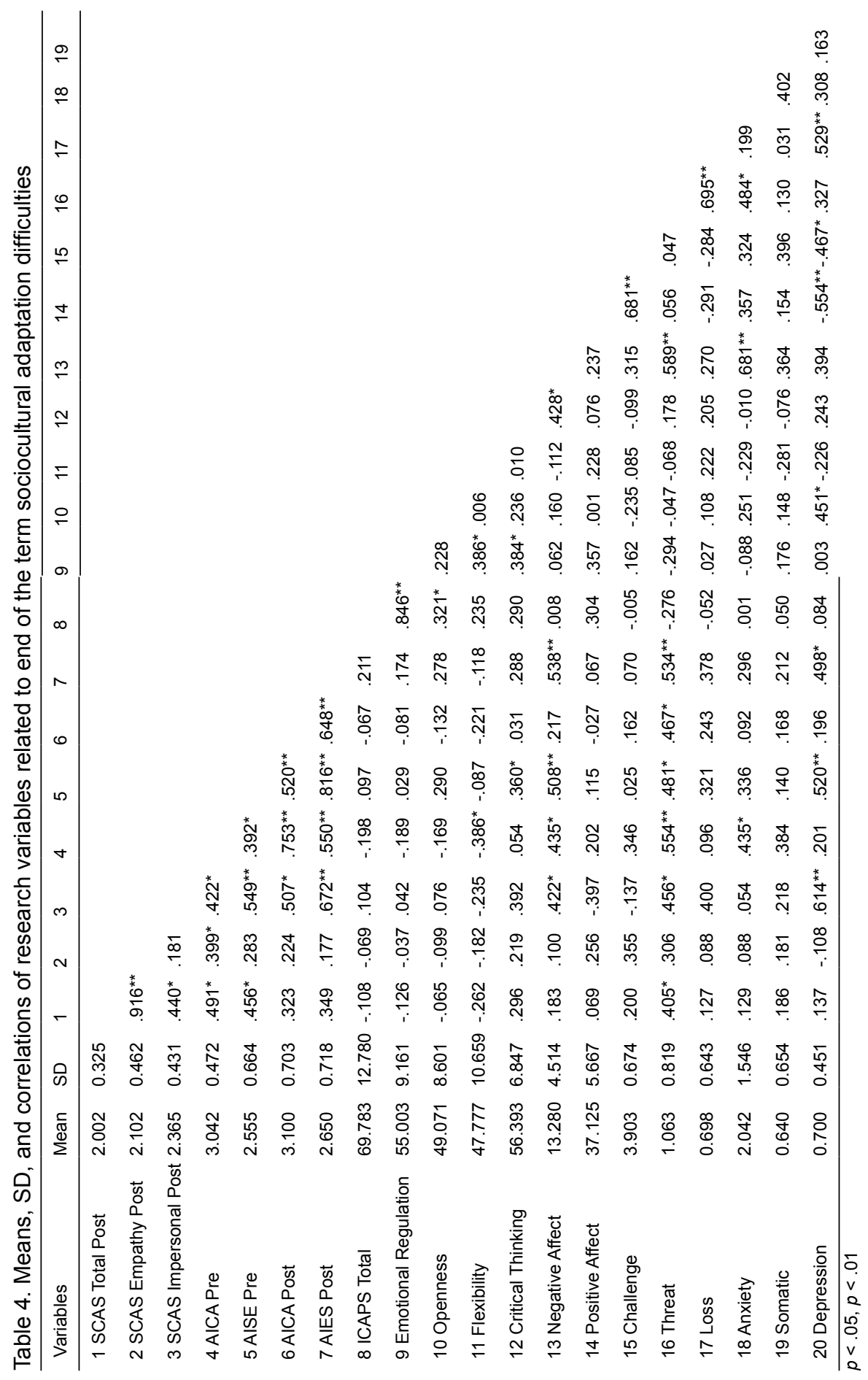




\section{Conclusions}

The null and sometime inverse relationships between the language fluency requirement and various study abroad outcomes in this study raise several questions. One key question is how much students actually used their acquired language to interact with host culture nationals. It may be that merely instituting language fluency as a requirement for entry into a study abroad site does not necessarily translate into students using that language actively on a day-to-day basis outside of classes. Psychological variables such as anxiety, motivation, and confidence concerning one's fluency may make it difficult for students to transfer what they have learned in the classroom to real-life interactions (Churchill \& Dufon, 2006). Unfortunately, we have neither measure of the quality of language use nor the intensity of actual interaction that occurred. Those measures should be incorporated into future research.

Also on a methodological level, it may be that other, unassessed differences between the programs being compared accounted for the research findings. The Oviedo and Vienna programs were similar in many respects; however, the requirement for language fluency for entry might not have been the only important difference. Although the two cultures differ by only two points on a cultural distance measure (Kogut $\&$ Singh, 2001), the ease of access into the culture, availability of English-speaking host nationals, acceptance of nonnative students into the local flow of activities all may contribute to the feeling of being able to fit in. Future studies should attempt to account for some of these variables.

Nevertheless, it may be useful to speculate about what, beyond language fluency, may have eased or hindered students' adaptation to their host cultures. As Deardorff (2008) says in her treatise on intercultural competence, "one component alone is not enough to ensure competence, i.e., either cultural knowledge or language by itself" (p. 33). She also states "the intercultural experts did not reach consensus on the role of language in intercultural competence: some felt that it was an essential component while others did not, citing that one may be fluent in a language but still not be interculturally competent" (p. 33). Rather, the key factor might be "sociolinguistic awareness;" that is, a recognition of how one uses language within a societal and social context, rather than fluency alone (Deardorff, 2008). Fluent students may have had some difficulty moving beyond grammar and syntax in the production of speech, while non-, or minimally fluent students may have focused more on how to use their rudimentary language to enter the culture regardless of correct vocabulary or structure. To some degree, this difference may reflect a student's relative cognitive strengths. Sternberg's Triarchic Model of Intelligence (1985) posits a difference between analytic thinking (necessary 
for language acquisition) and practical thinking (necessary for adept day-today functioning). The two "intelligences" do not necessarily coincide in any individual's cognitive repertoire. A question here is how much language fluency is enough to support students in medium term (three month) programs so that they can fit in satisfactorily? Results in the current study echo findings by Norris and Steinberg (2008) that a large proportion of positive outcomes for study abroad students was not dependent on fluency in the host culture language.

Further, we might question how much adaptation to a host culture is possible or even desirable given the shortness of the study abroad sojourn. Ward and Kennedy (1999) report that sociocultural adaptation levels off after roughly six months of living in a foreign culture. For the students in this study, who stayed only three months, the process of adaptation was neither smooth nor unidirectional. Clear ups and downs existed. It may be that interrupting the adaptation process at three months short-circuits the trend of fitting-in better and better. Additionally, the pattern of a rebound of difficulties reported in the SCAS and its Cultural Empathy and Impersonal Perils factors may indicate that in anticipation of returning to their home culture, students were faced with a starker distinction between home and host cultures. Savicki and Cooley (2011) postulate that anticipatory contact with other cultures may serve to initiate intergroup and symbolic anxiety. This could also be true in anticipation of return to one's home culture.

More broadly, an argument can be made that the realization by language fluent students that they will not be able to fit into their host culture to the degree to which they may have hoped is more realistic; therefore, more psychologically healthy. Such reactions may foreshadow entry into the Acceptance phase of the Developmental Model of Intercultural Sensitivity (Bennett, 1993). This more forceful realization by students with language fluency may reflect a more accurate assessment of both home and host cultures by virtue of having accessed the host culture more intensely via the host culture language. Whereas non-fluent students would not understand the host culture enough to even know how much they did not know about it. The very result that seemed at first glance to be negative (more intense adaptation difficulties) may, in fact, be a reflection of a more reality-based recognition that was not available to students who could not access the host culture as fully.

Additionally, language fluency may intensify the experience of intergroup anxiety (Voci \& Hewstone, 2003) by means of making recognition of differences between cultural assumptions of the groups more vivid. Such anxiety would also highlight perceived difficulties in adaptation.

Finally, this study's findings indicate that the role of anxiety in the study 
abroad experience may need to be further elaborated. Specifically, symbolic and inter-group contact anxiety (Stephan, Stephan \& Gudykunst, 1999) have been found to mediate the process of inter-group prejudice reduction (Voci \& Hewstone, 2003). In the current study, the stronger and more rigidly held students' pre-departure American identities, the more difficulties they had in adapting. Likewise, the more they engaged in exploring and examining their identity prior to departure, the more difficulties they had in fitting in by the end of their sojourn. The contrasts between home and host cultures are inevitable; indeed, they are fodder for the development of intercultural competence. Yet, these contrasts painfully prod at the core of the students' selves. Contrasts make evident that one's worldview, the seeming bedrock assumptions of one's reality, is actually only one of many ways to view the world. These challenges to one's identity are what make the study abroad experience so fulfilling, exciting and, at the same time, sometimes frightening. The challenge for both students and international educators is to simultaneously hold up for examination both host and home culture premises, while providing safety and support for continued examination.

A common student reaction to studying a foreign language in a study abroad setting is "fear of being absorbed by the culture of the language they are studying" (Paige, et al., 2003, p. 190). The concept of symbolic anxiety (Stephan \& Stephan, 1985) provides a model to understand this process. Symbolic anxiety occurs when the awareness of an alternate view of reality calls into question one's own view. An underlying presupposition is that there is one "right" view; thus if students accept the other view, then they necessarily reject their own view. Clearly, such thinking limits exploration, and may provoke anger and attack on alternate views. Such a result falls into the Defense categorization in Bennett's (1993) Developmental Model of Intercultural Sensitivity. In this stage, students might be expected to denigrate the values of the host culture and over identify with their own culture, much as some students in the current study may have done.

Somewhat paradoxically, we want to encourage the process of social identification that is represented by American identity as a healthy task of adolescent development; yet that identification and the process of pondering about it may interfere with some of the goals of study abroad. The resolution of this paradox remains a challenge for all involved in the study abroad enterprise.

In summary, language learning is neither a necessary nor sufficient cause for intercultural competence. Previous literature indicates that intercultural competence can be learned in cultures speaking the native tongue of the study abroad student (Norris \& Steinberg, 2008); and that there can be a disconnect between language learning and cultural learning (Paige, et al., 2003). The 
relationship between language fluency and intercultural competence has layers of complexity. Simply plunking students into a foreign culture guarantees neither increased language learning nor increased intercultural competence. In theory, these goals of study abroad should mutually reinforce each other, yet the methods to accomplish this end remain to be uncovered.

\section{References}

Allen, H.W. \& Herron, C. (2003) A Mixed-Methodology Investigation of the Linguistic and Affective Outcomes of Summer Study Abroad. Foreign Language Annals, 36, 370-385.

Baron \& Kenny (1986). The moderator-mediator variable distinction in social psychological research: Conceptual, strategic, and statistical considerations. Journal of Personality and Social Psychology. 6, 11731182.

Bennett, J. M. (2008). On becoming a global soul: A path to engagement on study abroad. In V. Savicki, (Ed). Developing Intercultural Competence and Transformation: Theory, Research, and Application in International Education (pp.13-31). Sterling, VA: Stylus Publishing.

Bennett, M. J. (1993). Towards ethnorelativism: A developmental model of intercultural sensitivity. In M. Paige (Ed.), Education for the intercultural experience (21-71). Yarmouth, ME: Intercultural Press. Inc.

Brown, H. E. (1998). Sojourner adjustment among undergraduate students: Relationships with locus of control and coping strategies. (Doctoral dissertation, The Claremont Graduate University, 1998. Digital Dissertations, 59/04, 1912.

Churchill, E. \& Dufon, M.A. (2006). Evolving threads in study abroad research. In M.A. Dufon \& Churchill, E. (Eds.). Language learners in Study Abroad Contexts, (pp1-27). Clevedon, UK: Multilingual Matters Limited.

Deardorff, D. K. (2008). Intercultural competence: A definition, model, and implications for education abroad. In V. Savicki, (Ed). Developing Intercultural Competence and Transformation: Theory, Research, and Application in International Education (pp. 32-51). Sterling, VA: Stylus Publishing.

Derogatis, L. R. \& Melisaratos, N. (1983). The brief symptom inventory: An introductory report. Psychological Medicine, 13, 595-605.

Edelstein, D. (2009). Only English spoken. Inside Higher Ed, Retrieved from http://www.insidehighered.com/views/2009/10/26/edelstein. 
Engle, L. \& Engle, J. (2003). Study abroad levels: Toward a classification of program types. Frontiers: The Interdisciplinary Journal of Study Abroad, IX, 1-20.

Engle, L. \& Engle, J. (2004). Assessing language acquisition and intercultural sensitivity development in relation to study abroad program design. Frontiers: The Interdisciplinary Journal of Study Abroad, X, 219-236. Ferguson, E. Matthews, G. \& Cox, T. (1999). The appraisal of life events (ALE) scale: Reliability and validity. British Journal of Health Psychology. 4, 97-116.

Hill, J. H. \& Mannheim, B. (1992). Language and world view. Annual Review of Anthropology, 21, 381-406

Isabelli-García, C. (2006). Abroad social networks, motivation and attitudes: Implications for second language acquisition. In M.A. Dufon \& Churchill, E. (Eds.). Language learners in Study Abroad Contexts, (pp. 231-258). Clevedon, UK: Multilingual Matters Limited.

Kogut, B., \& Singh, H. (2001). The effect of national culture on the choice of entry mode. Journal of International Business Studies, 19, 411-432. Lange, D. L. \& Paige,R. M. (2003). Introduction. In D. L. Lange \& R. M. Paige (Eds.) Culture as the Core: Perspectives on Culture in Second Language Learning (pp. ix-xvii). Greenwich, CT: Information Age Publishing.

Matsumoto, D., Leroux, J. A., Ratzlaff, C., Tatani, H., Uchida, H., Kim, C., \& Araki, S. (2001). Development and validation of a measure of intercultural adjustment potential in Japanese sojourners: The Intercultural Adjustment Potential Scale (ICAPS). International Journal of Intercultural Relations, 25, 483-510.

Meyer-Lee, E. \& Evans, J. (2008, May). New tools for intercultural outcomes learning assessment In D. Deardorff (Chair) Assessment toolbox for international educators. Symposium presented at the NAFSA Annual Conference, Washington, DC.

Norris, E. M. \& Steinberg, M. (2008). Does language matter? The impact of language instruction on study abroad outcomes. Frontiers: The Interdisciplinary Journal of Study Abroad, XVIII, 107-131.

Paige,R. M., Jorstad, H. L., Siaya, L., Klein, F., \& Colby, J. (2003). Culture learning in language education: A review of the literature. In D. L. Lange \& R. M. Paige (Eds.) Culture as the Core: Perspectives on Culture in Second Language Learning (pp. 173-236). Greenwich, CT: Information Age Publishing.

Phinney, J. S. (1992). The Multigroup Ethnic Identity Measure: A new scale for use with adolescents and young adults from diverse groups. Journal 
of Adolescent Research, 7, 156-176.

Phinney, J. S. \& Devich-Navarro, M. (1997). Variations in bicultural identification among African American and Mexican American adolescents. Journal of Research on Adolescence, 7, 3-32.

Savicki, V. \& Cooley, E. (2011) American identity in study abroad students: Contrasts and changes. Journal of College Student Development. 52, 339349.

Saville-Troike, M. (2003). Extending communicative concepts in the second language curriculum: A sociolinguistic approach. In D. L. Lange \& R. M. Paige (Eds.) Culture as the Core: Perspectives on Culture in Second Language Learning (pp. 3-18). Greenwich, CT: Information Age Publishing.

Stephan, W. G., \& Stephan, C. W. (1985). Intergroup anxiety. Journal of Social Issues, 41, 157-176.

Stephan, W. G., Stephan, C. W., \& Gudykunst, W. B. (1999). Anxiety in intergroup relations: A comparison of anxiety/uncertainty management theory and integrated threat theory. International Journal of Intercultural Relations, 23, 613-628.

Sternberg, R. J. (1985). Beyond IQ: A triarchic theory of human intelligence. NY: Cambridge University Press.

Voci, A. \& Hewstone, M. (2003). Intergroup contact and prejudice toward immigrants in Italy: The mediational role of anxiety and the moderational role of group salience. Group Processes and Intergroup Relations, 6, 37-54.

Ward, C. (2001). The A, B, Cs of acculturation. In D. Matsumoto (Ed.), Handbook of Culture and Psychology. (pp. 411-446). NY: Oxford University Press.

Ward, C., Bochner, S., \& Furnham, A. (2001). The Psychology of Culture Shock $2^{\text {nd }}$ Ed. London: Routledge.

Ward, C. \& Kennedy, A. (1999). The measurement of sociocultural adaptation. International Journal of Intercultural Relations 23. 659-677.

Watson, D, Clark L.A., Tellegen, A, (1988). Development and validation of brief measures of positive and negative affect: The PANAS scales. Journal of Personality and Social Psychology, 54, 1063-1070. 